\title{
ICAM-1: Contribution to Vascular Inflammation and Early Atherosclerosis
}

\author{
Sabine I. Wolf and Charlotte Lawson \\ Dept of Veterinary Basic Sciences, Royal Veterinary College \\ United Kingdom
}

\section{Introduction}

Atherosclerosis is a progressive chronic inflammatory disease characterised by the accumulation of lipids and fibrous elements in large arteries and increasingly threatens human health worldwide. Atherosclerotic lesion formation is a complex process which can proceed over decades. A number of different factors contribute to the formation of atherosclerotic lesions including the accumulation of lipids, activation of T-cells, transformation of macrophages into foam cells and proliferation of smooth muscle cells. The earliest events that lead to lesion formation are still very much under investigation. A number of risk factors have been identified that contribute to the pathogenesis of atherosclerosis, including hypertension, smoking, increased concentrations of plasma cholesterol, diabetes, obesity, age and male gender. All these risk factors can influence endothelial cell function resulting in increased permeability, increased adhesion of leukocytes and the expression of procoagulant molecules.

Intercellular adhesion molecule-1 (ICAM-1, CD54) is an immunoglobulin (Ig)-like cell adhesion molecule expressed by several cell types including leukocytes and endothelial cells. It is constitutively expressed at low levels on endothelial cells and leukocytes and upregulated following exposure to pro-inflammatory stimuli. ICAM-1 is important for the firm arrest and transmigration of leukocytes out of blood vessels and into tissue, as well as immunological synapse formation during $\mathrm{T}$ cell activation. It is present in atherosclerotic lesions and is involved in the progression of atherosclerotic lesions. We and others have shown that crosslinking of ICAM-1 on the cell surface leads to "outside in" signal transduction and to result in the initiation of several pro-inflammatory signalling cascades and rearrangement of actin cytoskeleton, leading to speculation that ICAM-1 "is more than just glue".

A soluble ICAM-1 molecule has been identified in serum, consisting of all five extracellular Ig-domains of membrane-bound ICAM-1-molecule, but lacking the transmembrane and cytoplasmic domains. sICAM-1 is present in normal human serum, whilst elevated sICAM-1 have been found in serum from patients with cardiovascular disease, cancer, autoimmune disease and several studies have correlated serum levels of sICAM-1 with severity of disease. Several studies have shown that sICAM-1 is able to bind to ligands of ICAM- 1 and a yet unknown receptor and is able to instigate signalling cascades. Here, we present our recent data which suggests that sICAM-1 acts as a pro-inflammatory agent when endothelial 
cells are subjected to prolonged arterial shear forces, including initiation of cytokine and chemokine expression, which could lead to monocyte attraction to inflamed regions of the vasculature.

\section{Atherosclerosis}

Atherosclerosis is a protracted, complex process, which takes place over several decades. The main contributing factors are lipid accumulation, activation of T-cells, transformation of macrophages into foam cells and the proliferation of underlying smooth muscle cells (Ross 1999; Lusis 2000).

Many theories have been discussed over the years about the initiation phase of atherosclerosis. William and Tabas suggested that a loss of endothelial cells within the blood vessel wall allowed increased permeability of leukocytes and lipoproteins into the subendothelial space and caused plaque formation (Williams and Tabas 1995). However, studies showing the presence of an intact endothelial cell layer at the site of plaque formation rejected the "endothelial cell denudation" theory. The theory was replaced by the "response to injury" hypothesis by Ross (Ross and Glomset 1974; Ross 1999). Ross suggested that injury of the endothelium lead to endothelial cell dysfunction and altered smooth muscle cell behaviour. Currently, more evidence points towards the "response to retention" hypothesis, which identified atherogenic lipoproteins as a key initiation step (Schwenke and Carew 1989; Schwenke and Carew 1989). The direct binding of these lipoproteins to the endothelium and the subsequent accumulation within the subendothelial space is thought to trigger endothelial cell activation, which is followed by an inflammatory response (Williams and Tabas 1995).

Apart from lipid there are a number of other factors that have been associated with accelerated cardiovascular disease and could contribute to vascular inflammation. It is widely appreciated that there is a greatly increased risk of cardiovascular disease with increase in body mass index independent of serum cholesterol (Lavie , Milani et al. 2009), and that patients with type II diabetes, chronic renal disease (Karalliedde, and Viberti 2004), and autoimmune disorders such as rheumatoid arthritis or lupus (Frostegård 2011) are far more likely to develop atherosclerosis independent of cholesterol and other traditional risk factors. A number of chronically infectious agents have also been linked to atherosclerosis including Chlamydia pneumoniae (Laurila, Bloigu et al. 1997) and Helicobacter pylori (Hoffmeister, Rothenbacher et al. 2001). These associations are likely to be due to an increase in systemic inflammation, characterised by chronically elevated levels of CRP and proinflammatory cytokines such as TNF-a, IL-1, IL-6. These circulating factors are all known to contribute to endothelial activation in vitro and to the expression of genes involved in vascular inflammation and atherosclerosis progression in vivo (Hansson 2009).

The earliest event visible within the blood vessel wall is the appearance of a "fatty lesion". These lesions can be found at branches, bifurcations and curvations of the arterial blood vessel walls (Lusis 2000). At these locations a disturbed flow pattern of the blood can be detected compared with the parallel (laminar) flow seen at "tubular" blood vessel sections. The disturbed shear stress at curved blood vessel locations activates endothelial cells and results in accumulation of lipoproteins (LDL), and activated macrophages within the subendothelial spaces. Skalen et al. (Skålén, Gustafsson et al. 2002) showed that lipoproteins initially bind to 
negatively charged sulphate groups on proteoglycans in the artery wall before translocating to the subendothelial space. The significance has been demonstrated in mice deficient in proteoglycans, which develop a reduced number of atherosclerotic lesions (Skålén, Gustafsson et al. 2002). Native LDL contributes to the inflammation at lesion site by undergoing modification by oxidation, lipolysis or proteolysis before being taken up by macrophages (reviewed by (Lusis 2000)). The uptake and accumulation of modified lipoproteins transforms the macrophages into foam cells, which are retained within the fatty streak.

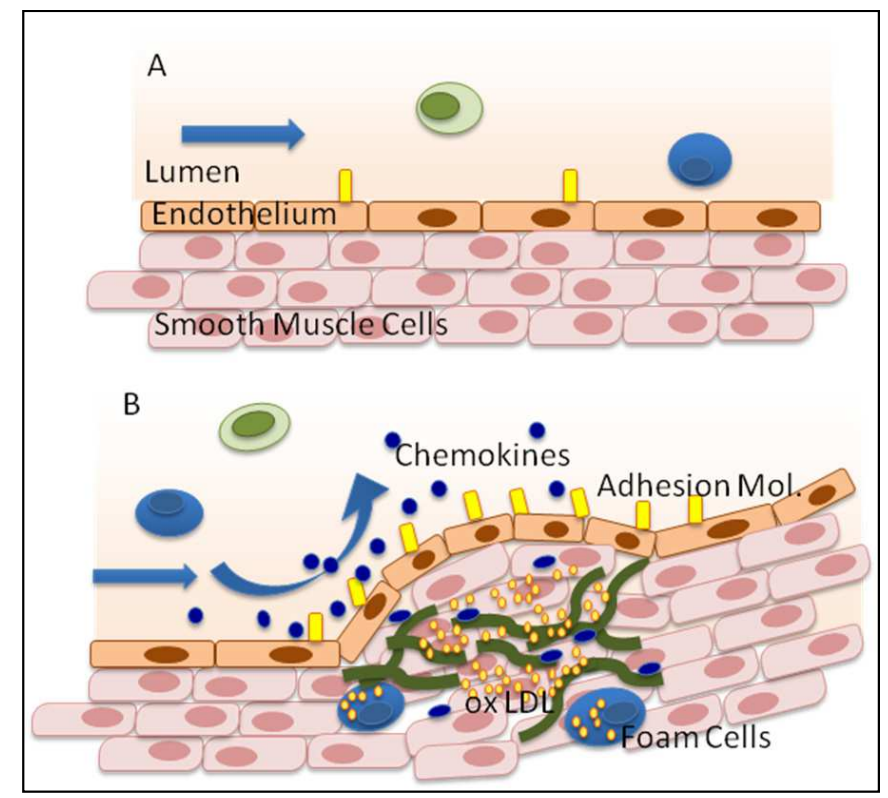

Fig. 1. Schematic cartoons showing healthy, tubular blood vessel (A) and curved blood vessel with plaque formation in process (B).

Oxidised LDL also contributes to the progression of the early lesion by itself stimulating endothelial cells to produce pro-inflammatory molecules, which leads to the recruitment of further immune cells. One important molecule released is the chemokine CCL-2 (MCP-1), which is responsible for recruiting monocytes to the lesion site (Gerszten, Garcia-Zepeda et al. 1999). Activated endothelial cells upregulate adhesion molecules including ICAM-1 on their cell surface facilitating transmigration of further leukocytes. The inflammatory environment within the lesion leads to the migration and proliferation of smooth muscle cells, infiltration of immune cells including B-cells, dendritic cells, mast cells and T-cells as well as elaboration of a collagen-rich matrix (Hansson and Libby 2006). The advanced lesion consists of a core containing foam cells, lipids and necrotic debris, which is surrounded by smooth muscle cells. The growth is asymmetrical protruding into the lumen and resulting in further blood flow changes. The exact composition of the plaque dictates the stability of the plaque. The fibrous cap, which is produced by smooth muscle cells and influenced by immune cells, prevents the contact between blood components and pro-thrombotic material within the lesion. Thrombus formation occurs once the fibrous cap raptures and coagulation factors come into contact with contents of the lesion (Hansson and Libby 2006). 


\subsection{Role of endothelium}

All large blood vessels, including the vessels of the arterial tree, are made up of several distinct tissue layers: the intima, media and adventitia. The intima is the inner lining and is formed of a single continuous layer of endothelial cells on the luminal side with a specialised subendothelial basement membrane and the internal elastic lamina. Beneath this vascular smooth muscle cells, elastic and collagen fibres, together with the external elastic lamina, make up the media. A connective tissue sheath, which may be vascularised with vasa vasorum, forms the outer layer, the adventitia.

The vascular endothelium, located on the luminal side of the intima, functions as a highly selective barrier, and its restrictive permeability is a vital component in healthy blood vessels. However, studies during the last 20 years have shown that the endothelium does not act as a passive barrier as previously thought, but is highly dynamic and controls a variety of functions. It is involved in the regulation of vessel tone, coagulation and fibrinolysis, leukocyte adhesion, fluid and solute exchange and the control of smooth muscle cell growth (Ross 1999; Lusis 2000). Indeed endothelial dysfunction contributes to many cardiovascular conditions including atherosclerosis, hypertension, stroke, inflammation, vasospastic disorders, diabetic microangiopathy, autoimmune disease, hypercholesterolemia, thrombosis and tumour growth (reviewed by (Lusis 2000)).

Endothelial cells react to a number of different stimuli, they are not only exposed to humoral factors from the circulation, but they are also subject to a variety of biomechanical stimuli. They differ depending on their location within the vascular beds and exhibit varying phenotypes. They are responsive to the environment of their local tissue and change barrier function accordingly to requirement of the underlying tissue.

Endothelial cells form a tight monolayer with well organised cell-to-cell junctions. These junctions are held together strongly by homo- and heterophilic binding of a number of key adhesion molecules expressed on neighbouring endothelial cells. The junctions play a vital role not only in permeability control, but also regulate leukocyte trans-endothelial migration and endothelial cell growth. The most important molecules involved in the cell-to-cell junction are considered to be PECAM-1 and VE-Cadherin.

\subsection{Importance of flow}

Cyclic stretch, fluid shear stress and hydrostatic pressure are the three main hemodynamic forces present within the blood vessel (Gimbrone, Topper et al. 2000). The importance of each force varies between the different cell types within the blood vessel wall. Smooth muscle cells mainly respond to cyclic stretch, whereas shear stress is the major force experienced by endothelial cells ( $\mathrm{Li}$, Haga et al. 2005). Shear stress acts parallel to the vessel wall within the lumen. It has a uniform, laminar pattern in "linear", unbranched areas of the vasculature. Depending on the location and type of the blood vessel, the (positive) shear stress values range between $10-40$ dynes $/ \mathrm{cm}^{2}$ in the arterial network, and $1-20$ dynes $/ \mathrm{cm}^{2}$ in the venular microcirculation (Surapisitchat, Hoefen et al. 2001; Lehoux, Castier et al. 2006). Endothelial cells exposed to prolonged laminar shear stress align and elongate in the direction of flow by reorientating their actin cytoskeleton, microtubules and intermediate filaments (Resnick, Yahav et al. 2003). This arrangement reduces the mechanical load experienced by endothelial cells and induces a quiescent state in which apoptotic, 
inflammatory and atherogenic genes are suppressed (Resnick, Yahav et al. 2003). Endothelial cells themselves secrete a number of factors which contribute to this quiescent state, including the vasodilator nitric oxide $(\mathrm{NO})$ and the vasorelaxant $\mathrm{PGI}_{2}$. $\mathrm{NO}$ is released into the lumen of the blood vessel where it acts to inhibit the attachment of platelets and leukocytes onto the luminal surface of endothelial cells. NO is also secreted into the basal side and prevents growth of smooth muscles cells underneath the endothelium. NO has also been reported to suppress the activation of transcription factors for adhesion molecules including ICAM-1 (De Caterina, Libby et al. 1995; Lindemann, Sharafi et al. 2000). The lack of expressed adhesion molecules on the endothelium prevents vascular inflammation and irregular cell proliferation (Figure 2a).

Sites exposed to steady laminar flow with high shear stress are atheroprotective (Gimbrone, Topper et al. 2000). At bifurcations and bends in the vasculature the laminar flow pattern becomes disrupted and creates sites with recirculating blood flow. The shear stress values vary from negative, to zero to positive values (Resnick, Yahav et al. 2003). Sites experiencing turbulent and disturbed flow are prone to develop atherosclerosis (Figure 2b) (Gimbrone, Topper et al. 2000).

Endothelial cells have been shown to possess a variety of mechanoreceptors, which not only sense shear stress but are able to react to changes by influencing gene expression. Several different molecules have been identified on endothelial cells as mechanoreceptors including two members of the integrin family, $\alpha_{v} \beta_{3}$ (Tzima, del Pozo et al. 2001) and $\alpha_{5} \beta_{1}$ (Chen, Li et al. 1999). Changes in shear stress lead to integrin clustering, thereby triggering the recruitment of shc to their cytoplasmic tails. This results in the initiation of signal cascades, which leads to phosphorylation of MAPK-kinases ERK and JNK (reviewed by (Shyy and Chien 2002)). One important example of a receptor tyrosine kinase acting as a mechanosensor on the endothelium is VEGFR-2 (Chen, Li et al. 1999). Rapid and transient phosphorylation of the tyrosine residues within the cytoplasmic tail of VEGFR-2 and the association with shc has been observed upon exposure to shear stress (Chen, Li et al. 1999). Another important group of mechanoreceptors are G-proteins and /or G-protein coupled receptors. Gudi and colleagues (Gudi, Clark et al. 1996) reported that G-protein activation takes place immediately upon exposure. In addition, several ion channels that are sensitive to shear stress have been identified. Studies have shown that $\mathrm{K}^{+}$channels induce NO when exposed to shear stress in bovine aortic endothelial cells (Ohno, Cooke et al. 1995; Helmlinger, Berk et al. 1996; Yamamoto, Korenaga et al. 2000). The glycoprotein PECAM-1 (CD31), which is involved in endothelial cell to cell adhesion, has also been shown to be sensitive to changes in shear stress. It is thought that fluid shear stress disrupts the conformation of the cytoplasmic tail revealing two tyrosine residues and enabling signal transduction (Fujiwara, Masuda et al. 2001; Osawa, Masuda et al. 2002). Recently, monocilia on endothelial cells in chick embryos and primary cilia on human vascular endothelial cells have been found in regions exposed to low or oscillatory shear stress. These have been proposed to contribute to endothelial activation and dysfunction (Van der Heiden, Groenendijk et al. 2006; Van der Heiden, Hierck et al. 2008). Caveolae have also been suggested to act as mechanoreceptors. Caveolae are plasma membrane invaginations, rich in cholesterol and identified by the protein marker caveolin-1. It is thought that signalling is initiated by the shear stress- induced movements of these rigid structures, which contain Gcoupled receptors, $\mathrm{Ca}^{2+}$ channels, VEGFR-2 and eNOS (Frank and Lisanti 2006). Another possible mechanosensitive structure on the luminal surface of endothelial cells may be the 
polysaccharide network that makes up the glycocalyx. The glycocalyx is known to act as a selectively permeable barrier for macromolecules based on their size and charge. However, it is also thought to sense mechanical forces and transduce the signals into intracellular responses (Florian, Kosky et al. 2003; Thi, Tarbell et al. 2004).

A
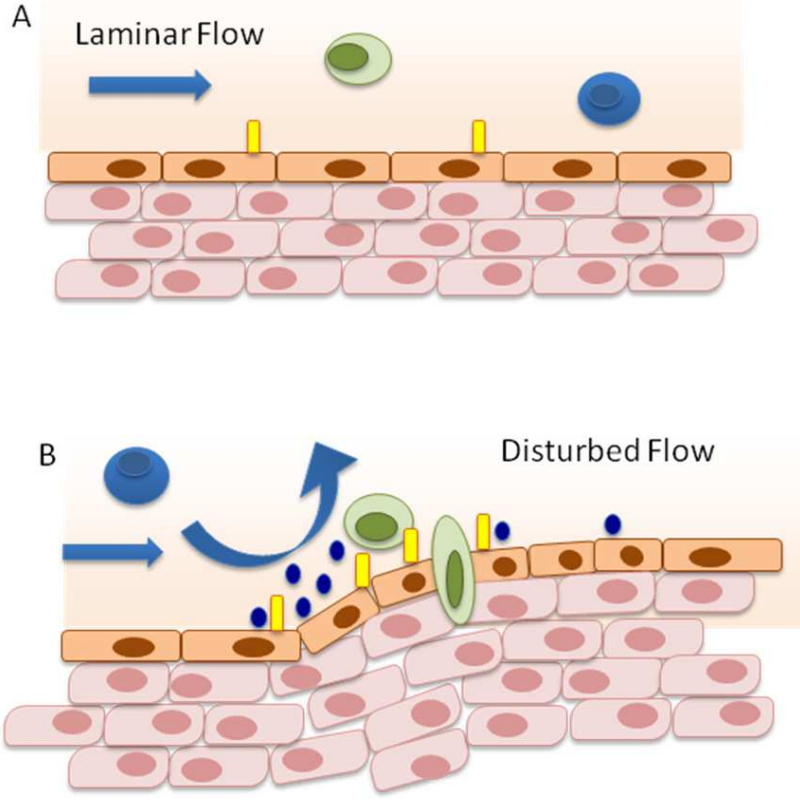

Fig. 2. Cartoon showing the different flow patterns experienced by endothelial cells. Parallel, laminar shear stress is present in unbranched, tubular parts of the blood vessel (A). Disturbed shear stress can be found at bends or bifurcation of blood vessels (B).

Depending on the type of blood vessel and the nature and strength of shear stress that the endothelium is subjected to in different locations in the vasculature, it is likely that a range of different mechanoreceptors are involved in mechanosensing and signal transduction. More research is required to identify the exact roles of each mechanosensor, the signalling pathways they activate and their contribution to endothelial activation or quiescence.

\subsection{Endothelial cell inflammatory responses}

There are a number of features of endothelial cell dysfunction including changes on the cell surface such as upregulation of adhesion molecules, exposure of pro-coagulant molecules, loss of highly selective barrier function and changes in vascular tone (reviewed by (Malyszko 2010)).

In quiescent, non-inflamed endothelial cells, NO prevents many responses leading to dysfunction and inflammation. However, once NO production is disrupted the brakes are removed from many of these harmful pathways. Oxidative stress within the endothelium has been reported as one of the key consequences of disrupted NO production, due to the formation of reactive oxygen species (ROS) and peroxynitrites. These harmful metabolic by- 
products can initiate pro-inflammatory signalling cascades, leading to upregulation of adhesion molecules including ICAM-1 and VCAM-1, chemokine and cytokine secretion. This contributes to increased monocyte adhesion and trans-endothelial migration. In addition ROS are responsible for oxidation of circulating lipoproteins. Together these events are very important for initiation of fatty streak formation in early atherosclerosis (reviewed by (Collins and Tzima 2011)).

\section{ICAM-1}

\subsection{Structure of ICAM-1}

Intracellular adhesion molecule 1 (ICAM-1, CD54) is a type I transmembrane glycoprotein, which belongs to the immunoglobin (Ig)-superfamily. It is constitutively expressed at basal levels on endothelial cells and leukocytes, but is upregulated by inflammatory stimulators such as TNF- $\alpha$ (Pober, Gimbrone et al. 1986), IFN- $\gamma$ (Dustin, Rothlein et al. 1986), IL-1 (Dustin, Rothlein et al. 1986) and LPS (Sampath, Kukielka et al. 1995) as well as shear stress (Nagel, Resnick et al. 1994). Upregulation of ICAM-1 is inhibited by glucocorticoids (Cronstein, Kimmel et al. 1992) and by IL-4 (Renkonen, Mattila et al. 1992).

ICAM-1 is encoded on seven exons with exon 1 encoding the signal sequence, exon 2 to 6 each extracellular Ig-domain and exon 7 the transmembrane and intracellular domains. The molecular weight ranges between $80-114 \mathrm{kDa}$ as the level of glycosylation varies heavily between different cell types. The ICAM-1 extracellular domain consists of 453 mainly hydrophobic amino acids, which form five Ig-domains with $\beta$-sheet structure, each Igdomain stabilised by disulfide bonds (Figure 3). The Ig-domains are followed by a single hydrophobic transmembrane region and a short 28 amino acid cytoplasmic domain, which is lacking any conventional signalling motifs. Tyrosine residues within the cytoplasmic tail have been shown to be important for intracellular ICAM-1 signalling (Tsakadze, Sen et al. 2004).

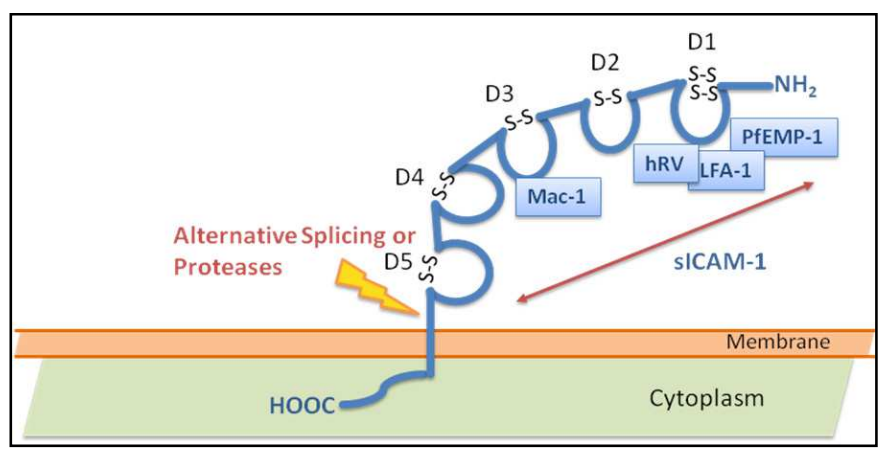

Fig. 3. Cartoon showing membrane bound ICAM-1 with its five Ig-domains (D1 - D5) and ligands LAF-1, mac-1, plasmodium falciparum erythrocyte membrane protein-1 (PfEMP-1) and human rhinovirus (hRV). Arrow indicates membrane region, which becomes cleaved off by proteases or alternative splicing releasing solube ICAM-1 (sICAM-1). (Adapted from Lawson and Wolf 2009 and Van de Stolpe and Van der Saag 1996).

Studies by Kirchhausen et al. (Kirchhausen, Staunton et al. 1993) have shown that ICAM-1 has a characteristic $140^{\circ}$ bend between domain 3 and domain 4 . This bend enables formation 
of homo dimers and multimers resulting in a "YYYY" configuration. The dimerisation is not required for ligand binding but increases binding avidity. The resulting stronger and prolonged interaction with its ligands is especially beneficial during antigen presentation and leukocyte transmigration.

\subsection{Ligands for ICAM-1}

ICAM-1 has several ligands including the membrane-bound $\beta 2$ integrin receptors CD11a/CD18 (LFA-1) and CD11b/CD18 (mac-1) present on leukocytes (Marlin and Springer 1987; Staunton, Marlin et al. 1988; Smith, Marlin et al. 1989) and fibrinogen (Languino, Plescia et al. 1993; Languino, Duperray et al. 1995; van de Stolpe and van der Saag 1996). A major group of human rhinovirus (Greve, Davis et al. 1989; Staunton, Merluzzi et al. 1989) and erythrocytes infected with plasmodium falciparum (Ockenhouse, Ho et al. 1991; Ockenhouse, Tegoshi et al. 1992) are also able to bind to ICAM-1.

The integrin ligands of ICAM-1 are members of the type I transmembrane heterodimeric glycoprotein family and consist of two non-convalently linked chains. LFA-1 and mac-1 possess the same $\beta_{2}$-integrin subunit (CD18) but different $\alpha$-chains namely $\alpha_{L}$ (CD11a) for LFA-1 and $\alpha_{M}$ (CD11b) for mac-1. Both integrins bind via an "inserted" (I) domain on the respective $\alpha$-chain to an acidic residue on ICAM-1. LFA-1 binds to glutamic acid (residue 34) on ICAM-1 in the presence of magnesium and calcium ions. The ligand binding results in a reorientation of glutamic acid positioned within the third domain (residue 241) and the formation of a critical salt bridge with lysine (residue 39). The binding site for integrin mac-1 is located within the third domain of ICAM-1 and is dependent on the glycosylation level. High levels of N-linked oligosaccharides sterically and electrostatically hinder access to the binding site. As the level of glycosylation is dependent on cell type, different cell types will allow a diverse ligand binding pattern. Activation of the integrins is required before binding of LFA-1 or mac-1 to ICAM-1 can occur. On resting cells, integrins exhibit a low affinity conformation for ligand binding. Following "inside-out" signalling, a conformational change takes places exposing a high affinity ligand binding site. Integrins play an important role in the immune system as demonstrated in patients with type I leukocyte adhesion deficiency (LAD), a rare autosomal recessive disorder, which causes a complete lack of $\beta_{2}-$ integrins. This deficiency causes severe defects in the inflammatory immune system and leads to multiple, chronic and life-threatening bacterial infections (Blankenberg 2003).

In addition to activated integrins, the majority of rhinovirus family (91 serotypes) and some members of the coxsackie virus A family bind ICAM-1 (Greve, Davis et al. 1989; Staunton, Merluzzi et al. 1989). The virus families bind to an epitope on domain one which lies directly next to LFA-1 (Staunton 1990) and overlaps with the one used by plasmodium falciparum infected erythrocytes (Ockenhouse, Betageri et al. 1992). Binding to ICAM-1 initiates the entry of the virus into the host cell (Bella and Rossmann 1999).

Another ligand, which has been shown to bind to ICAM-1 is fibrinogen (Altieri, Duperray et al. 1995). The plasma glycoprotein is involved in blood coagulation, inflammation and tissue repair (Tsakadze, Zhao et al. 2002). Its binding to ICAM-1 enables the adhesion of circulating platelets and inflammatory cells to the endothelium and fibrinogen deposition, which can lead to increased leukocyte transmigration, endothelial cell survival and vasocontriction (Tsakadze, Zhao et al. 2002). 


\subsection{Function of ICAM-1}

The main function of ICAM-1 is to provide firm adhesion, a characteristic which is pivotal in leukocyte transendothelial migration and antigen presentation.

The leukocyte transmigration process, which is also called diapedesis, can be divided into four sequential, but overlapping steps as summarised in Figure 4 (Springer 1994):

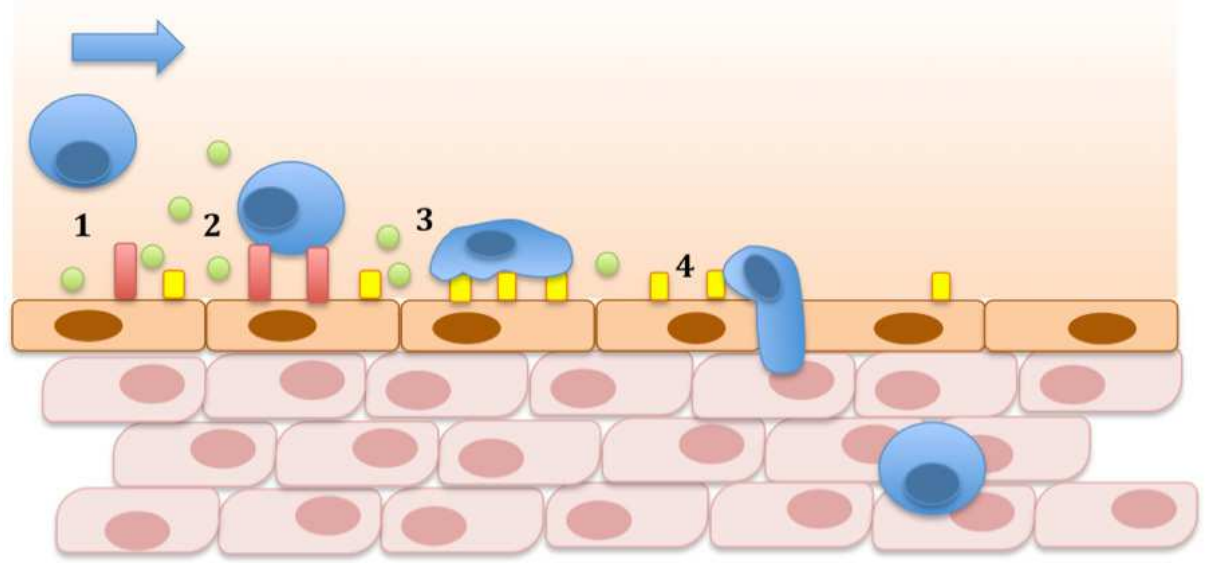

Fig. 4. Cartoon showing four subsequent transmigration steps: rolling (1), tethering (2), adhesion (3) and transmigration (4). (Adapted from Springer 1994).

The first transmigration step is mediated by selectin binding. Selectins from one cell interact with sialylated carbohydrates on the other, opposing cell. E- and P-Selectin present on endothelial cells loosely bind to sialyl Lewis ${ }^{\mathrm{x}}$ related carbohydrates on leukocytes and Pselectin glycoprotein ligand-1 (PSGL-1). L-selectin is present on all circulating leukocytes and binds to CD34, PSGL-1 and sialyl Lewis ${ }^{x}$ on endothelial cells. Loose binding of leukocytes to endothelial cells allows the cells to slow down and "roll" along the endothelium. It also facilitates the exposure to chemokines such as CCL-2, CXCL-8, CCL-5 and CCL-3. Patients with LAD II lack biosynthesis of fucose, which plays a pivotal role for carbohydrate ligand binding. LAD II is a milder form of LAD, but underlines the importance of selectin binding within the immune system (Blankenberg, Barbaux et al. 2003).

Chemokines play a pivotal role in the second transmigration step. Slow rolling leukocytes are directed by a chemokine gradient towards the dysfunctional endothelial site. The chemokine exposure triggers outside-in signalling events within leukocytes, which leads to integrin activation. Chemokines involved in leukocyte attraction and activation include CXCL-8 (neutrophils) and CCL-2 (monocytes).

The activated integrins on the surface of leukocyte are now able to firmly bind to the adhesion molecules present on the inflamed endothelium. Strong adhesion is facilitated by the binding of ICAM- 1 to LFA-1, VCAM- 1 to VLA- 4 and MADCAM- 1 to $\alpha_{4} \beta_{7}$. The binding allows leukocytes to spread and slowly migrate over the endothelial cell monolayer in search of transmigration opportunities. The importance of ICAM-1 within the third transmigration step has been demonstrated in studies using anti-ICAM-1 blocking 
antibodies or endothelial cells lacking ICAM-1 (Greenwood, Wang et al. 1995; Reiss and Engelhardt 1999; Lehmann, Jablonski-Westrich et al. 2003).

The junction proteins PECAM-1, VE-cadherin, junctional adhesion molecules (JAMs) and CD99 are found in endothelial junctions. Their homophilic (PECAM-1, CD99 and JAMs) and heterophilic binding (JAMs with integrins) allow the formation of a tightly packed endothelial cell layer with very selective permeability (Ley, Laudanna et al. 2007). When leukocytes are firmly attached to the endothelium, they develop microvilli-like projections called podosomes, with which they probe the endothelial surface (Barreiro, Yanez-Mo et al. 2002). These docking stations are rich in ICAM-1 and VCAM-1 and F-actin. Integrin binding initiates signalling events in endothelial cells, which is thought to lead to endothelial cell contraction and weakening of junctional bonds (reviewed by (van Buul and Hordijk 2004)). Studies using ICAM-1 deficient cells show reduced transmigration events, but not complete inhibition. This shows that ICAM-1 is involved in the final leukocyte transmigration step but not essential, similar to CD18 (Sligh, Ballantyne et al. 1993; Lehmann, Jablonski-Westrich et al. 2003). Once the junctional adhesion molecule bonds are released leukocytes are able to migrate into the underlying tissue (Springer 1994).

Another very important event in which ICAM-1 plays a vital role is the immunological synapse. This event is characterised by three major events: junction formation, reorganisation and the formation of a stable immunological complex (Grakoui, Bromley et al. 1999). During the first step, the junction formation, close contact between an antigen presenting cell (APC) and T-cell is facilitated with the help of ICAM-1 and LFA-1. The binding of ICAM-1 to its ligand overcomes the steric hindrance from glycoproteins CD45 and CD43 present on the cell surface for the T-cell receptor (TCR) complex and enables interaction with MHC-peptide present on APCs. In the event of low affinity between the TCR and MHC-peptide complex, the interactions between the two cells stops here. If the TCR and MHC-peptide complex show high affinity towards each other, a signal cascade is triggered, which leads to reorganisation of the molecules involved. TCR and MHC-peptide complexes move inwards towards the centre with the outwards moving LFA-1/ICAM-1 molecules forming a tight circle around them. This reorganisation step allows the formation of a stable immunological complex. During this reorganisation and ring formation process, ICAM-1 polymerises, thereby exhibiting higher affinity binding to LFA-1. In addition, concentrating TCR-MHC-peptide complexes within the ring centre facilitates optimal communication between the cells and signalling cascade (Grakoui, Bromley et al. 1999).

ICAM-1 has also been reported to act as costimulatory ligand during MHC I and MHC II restricted antigen presentation (Gaglia, Greenfield et al. 2000).

ICAM-1 has been shown to be present in atherosclerotic lesions (Poston, Haskard et al. 1992) and involved in the progression of atherosclerotic lesions. The involvement of ICAM-1 in atherosclerosis has been demonstrated in apoE $\%$ mice deficient in ICAM-1, which had reduced lesion size (Nageh, Sandberg et al. 1997). Time course analysis revealed that ICAM1 is not only involved in the initial plaque formation but also in subsequent progression in mice (Bourdillon, Poston et al. 2000; Kitagawa, Matsumoto et al. 2002). These data were supported by results obtained in apoE $\%$ mice treated with anti-ICAM-1 neutralising antibodies (Patel, Thiagarajan et al. 1998). 


\subsection{Signalling via ICAM-1}

The Outside-in signalling event triggered by ICAM-1 multimerisation was discovered several years ago (Durieu-Trautmann, Chaverot et al. 1994; Rothlein, Kishimoto et al. 1994). Experimental methods to identify the mechanism underlying the signalling cascade include co-cultures of endothelial cells with leukocytes, immobilised fibrinogen and antibodycrosslinking of ICAM-1 on the cell surface. The cytoplasmic tail of ICAM-1 does not contain any conventional intrinsic kinase activity or known protein-protein interaction domains, that could contribute to signalling cascades, but does contain a high number of positively charged amino acids and one tyrosine site (Lyck, Reiss et al. 2003). Adapter molecules, which have been linked to the signalling cascade depend partly on the vascular bed from which endothelial cells originate and the experimental in vitro model used. Molecules which have been associated with ICAM-1 include: alpha-actinin (Carpén, Pallai et al. 1992), ERMproteins (Wójciak-Stothard, Williams et al. 1999), cortactin (Durieu-Trautmann, Chaverot et al. 1994), beta-tubulin and glyceraldehyde-3-phsophate dehydrogenase (Federici, Camoin et al. 1996). The Src-homology domain 2 has been shown to bind in a phosphotyrosine dependent manner following the activation of ICAM-1 by fibrinogen (Pluskota, Chen et al. 2000; Pluskota and D'Souza 2000). These findings were opposed by Lyck et al (Lyck, Reiss et al. 2003), who showed that brain EC lacking the phosphotyrosine within ICAM-1's cytoplasmic tail are still capable of facilitating transmigration of T-cells. Activation of srckinase family members p53/p65lyn have been reported in B-cells following crosslinking of ICAM-1 (Holland and Owens 1997).

The small GTPase rho, has been proposed as another important molecule in the ICAMsignalling cascade and the resulting rearrangement of the actin cytoskeleton (Etienne, Adamson et al. 1998; Adamson, Etienne et al. 1999; Wójciak-Stothard, Williams et al. 1999; Thompson, Randi et al. 2002). Mutagenesis of a five amino acid fragment within the cytoplasmic tail identified RKIKK as an important sequence, which seemed to be involved in rho activation following ICAM-1 crosslinking by antibodies on the cell surface (Oh, Lee et al. 2007). Activation of rho has been shown to trigger phosphorylation of focal adhesion kinase, paxillin and p130 as well as activation of JNK (Etienne, Adamson et al. 1998).

Production of reactive oxygen species, which is required for activation of src tyrosine kinase has been observed when crosslinking ICAM-1 on pulmonary microvascular EC (Wang, Pfeiffer et al. 2003). Activation of src kinase is required for initiating ERM-molecule ezrin and p38 MAPK kinase pathway. Further signalling components initiated by ICAM-1 crosslinking on brain microvascular EC are intracellular calcium release and activation of protein kinase $\mathrm{C}$, which are thought to lead to phosphorylation of cortactin (EtienneManneville, Manneville et al. 2000).

MAPK-kinase pathways ERK-1/2 and/or JNK have been shown to the triggered depending on experimental design and cell type (Etienne, Adamson et al. 1998; Sano, Nakagawa et al. 1998; Lawson, Ainsworth et al. 1999; Lawson, Ainsworth et al. 2001). We have demonstrated that AP-1 activation is the result of ERK-1 activation (Lawson, Ainsworth et al. 1999), together with the ERK-dependent production and secretion of IL-8 and RANTES (Sano, Nakagawa et al. 1998) as well as upregulation of VCAM-1 on the cell surface (Lawson, Ainsworth et al. 1999; Lawson, Ainsworth et al. 2001). Recently we have also shown that patient auto-reactive antibodies against ICAM-1 can also cause endothelial cell signalling (Lawson, Holder et al. 2005). 


\subsection{Importance of ICAM-1 polymorphism in different vascular diseases}

Two single-base pair polymorphisms of ICAM-1 have been described, which are located in exon 4 and exon 6 . The first modification in exon 4 substitutes the amino acid glycine with arginine at codon 241 within the third Ig-domain. The second polymorphic change is located within the $5^{\text {th }}$ domain at codon 469 and replaces glutamic acid with lysine. Domain four and five do not bind any ligands, but are involved in the protein stability and therefore might affect ligand binding. The polymorphic substitution has been associated with coronary heart disease, myocardial infarction (Jiang, Klein et al. 2002) and peripheral artery disease (Gaetani, Flex et al. 2002) but larger studies are required to confirm the association. We have shown an increase in cell surface expression of both endogenous and transfected ICAM-1 G241/E469 genotype, which may account for some of the genetic associations that have been reported (Holder 2008).

\section{Soluble ICAM-1}

A circulating form of ICAM-1 consisting of only the five extracellular Ig-domains has been identified. Soluble ICAM-1 (sICAM-1) lacks the transmembrane region and cytoplasmic tail of membrane bound ICAM-1.

sICAM-1 has been detected in various body fluids including serum (Rothlein, Mainolfi et al. 1991; Seth, Raymond et al. 1991), cerebrospinal fluid (Tsukada, Matsuda et al. 1993), synovial fluid (Mason, Kapahi et al. 1993), sputum (Chihara, Yamamoto et al. 1994), urine (Teppo, von Willebrand et al. 2001) and bronchoalveolar fluid (Shijubo, Imai et al. 1994). sICAM-1 is present in normal human serum at concentrations between 100-450 ng/ml (Gearing and Newman 1993), whilst elevated sICAM-1 has been found in serum from patients with cardiovascular disease, cancer, autoimmune disease and several studies have correlated serum levels of sICAM-1 with severity of disease (for review see (Witkowska and Borawska 2004)).

The molecular weight of monomeric sICAM-1 varies between $80-110 \mathrm{kDa}$ depending on the level of glycosylation induced by the originating cell (Rothlein, Mainolfi et al. 1991). Studies have demonstrated that sICAM-1 is present in serum not only as monomer but also forms homo- and hetero-multimers with isoforms ranging from 240, 340 and over 500kDa (Rothlein, Mainolfi et al. 1991; Seth, Raymond et al. 1991).

A variety of cells have been shown to express sICAM-1 including primary endothelial cells, human aortic smooth muscle cells, melanoma cells and hematopoietic cell lines, but no expression mechanism has been identified. Alternative splicing has been suggested as one mechanistic pathway for the production of sICAM-1 (Wakatsuki, Kimura et al. 1995). The inflammatory cytokines TNF- $\alpha$, IL- $1 \alpha$ and IFN- $\gamma$ have been reported to induce shedding of sICAM-1 from the cell surface of different primary cells and cell lines (Becker, Dummer et al. 1991; Leeuwenberg, Smeets et al. 1992; Pigott, Dillon et al. 1992; Fonsatti, Altomonte et al. 1997; Leung 1999). Furthermore, several proteases including matrix metalloproteases (MMP) (Lyons and Benveniste 1998); Tarín, Gomez, et al. 2009), human leukocyte elastase (Champagne, Tremblay et al. 1998) and TNF- $\alpha$ converting enzyme (TACE) (Tsakadze, Sithu et al. 2006) have been demonstrated to cleave sICAM-1 from the cell surface. The cleavage site on ICAM-1 seems to vary depending on cell type, glycosylation pattern and therefore 
also on the proteases involved. Further analysis showed that cleavage of membrane bound ICAM-1 by MMP-13 is dependent on NO and might be part of NO-mediated atheroprotection (Tarín, Gomez et al. 2009).

\section{1 sICAM-1 as a biomarker in vascular disease}

Increased levels of sICAM-1 have been found in patients with cardiovascular disease, cancer, autoimmune disease. Studies investigating the involvement of sICAM-1 in tumour surveillance by interfering with T-cell and tumour interaction have demonstrated that levels of sICAM-1 correlated with tumour progression in melanoma (Giavazzi 1992) and colorectal cancer (Alexiou 2001). Increased levels of sICAM-1 have also been linked to progression of atherosclerotic lesions in apoE /- mice (Kitagawa, Matsumoto et al. 2002). These findings were supported in clinical studies with patients suffering from coronary heart disease (Hwang, Ballantyne et al. 1997; Ridker, Hennekens et al. 1998). Investigation between different risk factors associated with atherosclerosis showed a link between intake of saturated fatty acids and elevated levels of sICAM-1 (Bemelmans, Lefrandt et al. 2002). Increased levels of sICAM-1 were also found in type 2 diabetic patients (Becker, van Hinsbergh et al. 2002). Serum levels of sICAM-1 in cardiovascular patients treated with statins were confirmed to be lower in some groups (Romano, Mezzetti et al. 2000; Blann, Gurney et al. 2001; Bickel, Rupprecht et al. 2002), whereas some studies could not find a significant reduction (Rauch, Osende et al. 2000; Jilma, Joukhadar et al. 2003).

The use of sICAM-1 as a biomarker has lead to several studies with a range of different cardiovascular disease profiles and varying patient numbers. A significant correlation between future coronary artery disease events and elevated levels of sICAM-1 has been noted by several groups (Hwang, Ballantyne et al. 1997; Ridker, Hennekens et al. 1998; Malik, Danesh et al. 2001) but opposed by other studies (Ridker, Buring et al. 2001). Using sICAM-1 levels as biomarker for future secondary cardiovascular diseases in patients with coronary artery diseases again showed varying results with Blankenberg et al. (Blankenberg, Rupprecht et al. 2001) finding no significant correlation, a finding contradicted by others showing its potential as independent biomarker (Wallén, Held et al. 1999; Haim, Tanne et al. 2002).

Several genome studies have found a significant link on chromosome 19 close to the location of the ICAM-1 gene which might be responsible for elevated sICAM-1 levels (Kent, Mahaney et al. 2007; Bielinski, Pankow et al. 2008; Barbalic, Dupuis et al. 2010). Furthermore, Kent and colleagues (Kent, Mahaney et al. 2007) suggested the presence of SNPs within ICAM-1 to be involved in regulation of protein expression, function and its potential for cleavage. Several studies have examined the association of the SNPs within the ICAM-1 gene and sICAM-1 with atherosclerosis but have so far proved inconclusive (Tang, Pankow et al. 2007; Bielinski, Pankow et al. 2008; Bielinski, Reiner et al. 2011). Further clinical studies with larger patient numbers are required to clarify the situation.

\subsection{Pro-inflammatory signalling cascades initiated by SICAM-1}

Studies have reported that sICAM-1 binds competitively to ligands of membrane bound ICAM-1 such as LFA-1, mac-1 and human rhinovirus (Marlin, Staunton et al. 1990; Martin, Martin et al. 1993) and may therefore have potential as a therapeutic to block 
leukocyte:endothelial interactions when administered at high concentrations. However, a number of studies have also shown that addition of sICAM-1 at a physiologically relevant concentration activates proinflammatory cascades and causes angiogenesis in different in vitro and in vivo models. Incubation of murine brain microvascular EC or astrocytes with sICAM-1 lead to the increased secretion of the proinflammatory chemokine MIP-2 via activation of src tyrosine kinase and Erk phosphorylation (Otto, Heinzel-Pleines et al. 2000; Otto, Gloor et al. 2002). Gho and colleagues investigated the effects of sICAM-1 on EC angiogenesis. They demonstrated that sICAM-1 stimulated chemotactic EC migration, EC tube formation on Matrigel and sprouting in an aortic ring assay (Gho, Kleinman et al. 1999) and stimulates tumor growth in vivo (Gho, Kim et al. 2001). These data suggest that sICAM1 could contribute to the progression of atherosclerosis and other chronic inflammatory diseases.

\section{3 sICAM-1 contributes to monocyte recruitment by endothelial cells under laminar flow}

Whilst the effect of sICAM-1 interaction with endothelium has been documented during static culture conditions, it is pertinent to investigate the biological effects of these interactions using a model of arterial flow to replicate the forces applied to EC under physiological conditions. We have used a parallel plate chamber and flow loop (see Macey, Wolf et al. 2009; Macey, Wolf et al. 2010; Lawson, Rose et al. 2010) to examine sICAM-1 mediated pro-inflammatory effects on human umbilical vein EC (HUVEC) acclimatised to arterial flow conditions. These may provide useful insights into the initiation of endothelial dysfunction and inflammatory activation that is a feature of atheroma progression.

We subjected HUVEC to laminar flow of $10 \mathrm{dyn} / \mathrm{cm}^{2}$ for $8 \mathrm{~h}$ and analysed the cells for changes in Erk-1/-2 phosphorylation (phospho-Erk) as an indication of HUVEC activation after exposure of cells to flow for different times. As shown in Figure 5A the level of phospho-Erk was reduced to $42 \pm 7 \%$ after exposure to $10 \mathrm{dyn} / \mathrm{cm}^{2}$ flow for $8 \mathrm{~h}$ compared to HUVEC in static culture $(\mathrm{p}<0.001)$. Levels of phospho-Erk in HUVEC subjected to flow remained below phospho-Erk in equivalent static cultures for at least a further $24 \mathrm{~h}$ (data not shown). sICAM-1 has been shown to induce phospho-Erk in mouse astrocytes in static culture (Otto, Gloor et al. 2002), we therefore examined the effect of sICAM-1 in HUVEC pre-exposed to $10 \mathrm{dyn} / \mathrm{cm}^{2}$ flow. As seen in Figure $5 B$ in HUVEC pre-exposed to flow for 8hr followed by sICAM-1 incubation caused a transient elevation of phospho-Erk after 15min (Figure 5B $292 \pm 28 \%$ of untreated flowed HUVEC $\mathrm{p}<0.01$ ).

In static cell culture, sICAM-1 at physiologically relevant concentrations has been reported to induce expression of pro-inflammatory mediators (Otto, Heinzel-Pleines et al. 2000; Otto, Gloor et al. 2002). mRNA levels of IL-8 and MCP-1 were significantly increased $1 \mathrm{hr}$ after exposure to sICAM-1 in HUVECs (figure 6A and B). However, we observed no significant effect of sICAM-1 on secretion of MCP-1 and IL-8 in HUVEC cultured under static conditions (Figure 6C and D). Secretion of both chemokines were significantly reduced in EC exposed to $10 \mathrm{dyn} / \mathrm{cm}^{2}$ shear forces for $24 \mathrm{~h}$ compared to static cultures (Figure 6C and D) after acclimatisation to shear stress as would be expected from previous reports (Metallo, Vodyanik et al. 2008). Addition of sICAM-1 to the culture media of HUVEC pre-exposed to 
shear and with continued exposure to shear lead to a three fold increase in MCP-1 secretion (Figure 6C), but did not induce any changes in IL-8 levels (figure 6D). To determine whether sICAM-1 mediated phosphorylation of Erk-1/-2 is involved in the upregulation of MCP-1 secretion, $1 \mu \mathrm{M}$ of the MEK inhibitor U0126 or its inactive analogue U0124 was added to HUVEC pre-exposed to flow and prior to addition of sICAM-1 to the flow medium. As seen in Figure 6E, there was no significant effect of U0124 on this $(1949 \pm 123 \mathrm{pg} / \mathrm{ml}$ sICAM-1 induced secretion vs $1645 \pm 73.58 \mathrm{pg} / \mathrm{ml}$ in the presence of $1 \mu \mathrm{M}$ U0124 and sICAM-1 $\mathrm{p}=0.1348 \mathrm{~ns}$ ). In contrast, a significant reduction in secretion of MCP- 1 was observed in cells pre-treated with $1 \mu \mathrm{M}$ U0126 prior to addition of sICAM-1 $(1141 \pm 128.4 \mathrm{pg} / \mathrm{ml}, \mathrm{p}=0.0177$ compared to cells treated with sICAM- 1 alone; $p=0.0039$ compared to cells treated with $1 \mu \mathrm{M}$ U0124 before sICAM-1 (Figure 6E)).

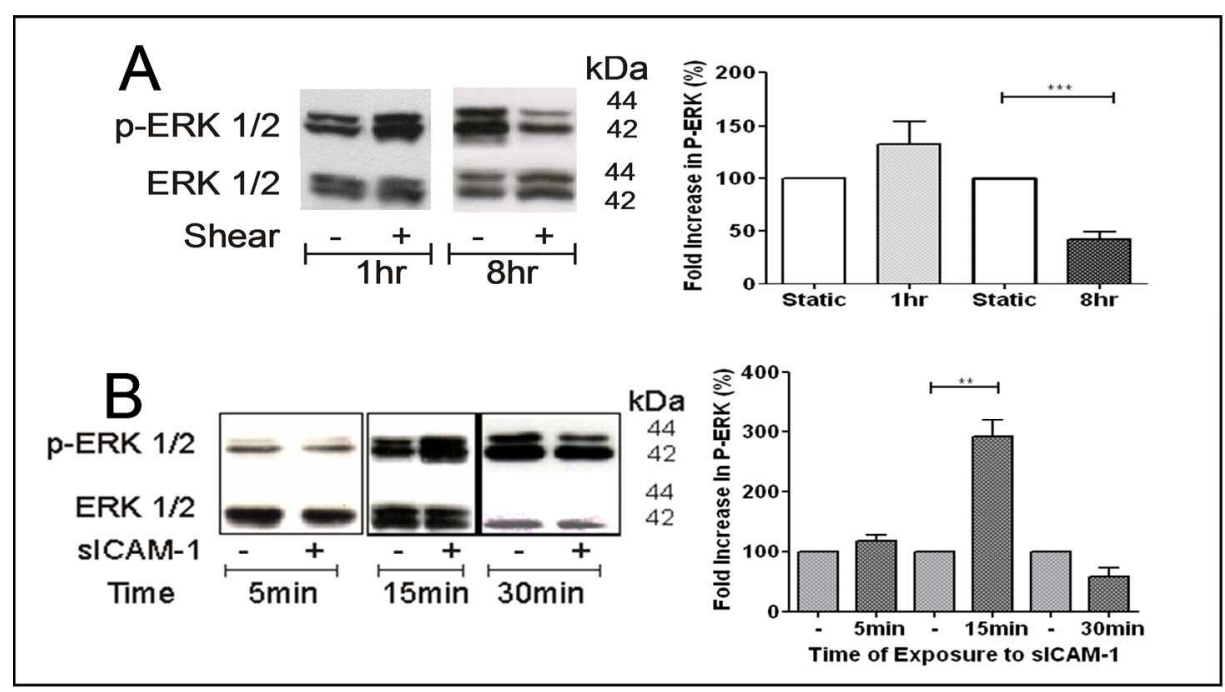

Fig. 5. sICAM-1 mediated Erk-1/-2 phosphorylation in HUVEC. A. HUVEC were subjected to laminar shear forces of $10 \mathrm{dyn} / \mathrm{cm}^{2}$ for $8 \mathrm{~h}$ in a parallel plate flow chamber and recirculating flow loop, or cells from the same isolate were maintained in static culture. Protein was harvested and phospho-Erk was measured by western blotting and immunodetection (anti-phospho-Erk-1/-2 antibody from Cell Signaling Inc.), followed by stripping of blots and detection of total Erk expression (anti-total-Erk-1/-2 antibody from Cell Signaling Inc.). Representative blots shown. Stimulation index was calculated from densitometry measured for each replicate and pooled from $n=3$ sets of replicates for each time point. B. HUVEC were subjected to laminar shear forces of $10 \mathrm{dyn} / \mathrm{cm}^{2}$ for $8 \mathrm{~h}$ in duplicate, before $100 \mathrm{ng} / \mathrm{ml}$ sICAM-1 was added to one culture from each duplicate for indicated times. Protein was harvested and phospho-Erk was measured by western blotting and immunodetection followed by stripping of blots and detection of total Erk expression. Representative blots shown. Stimulation index calculated from densitometry measured for each replicate and pooled from $n=3$ sets of replicates for each time point. Pooled stimulation index data was used for paired $\mathrm{T}$ tests calculated using Prism. ${ }^{* *} \mathrm{p}<0.01,{ }^{* * *} \mathrm{p}<0.001$ 


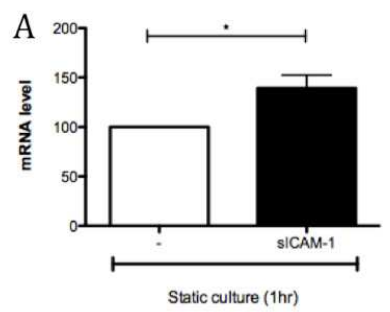

$\mathrm{B}$
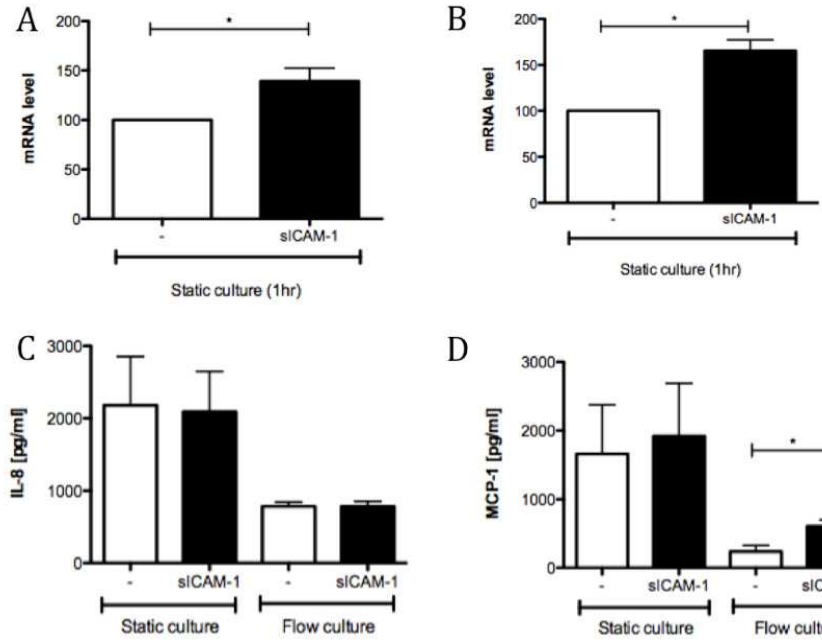

$\mathrm{D}$
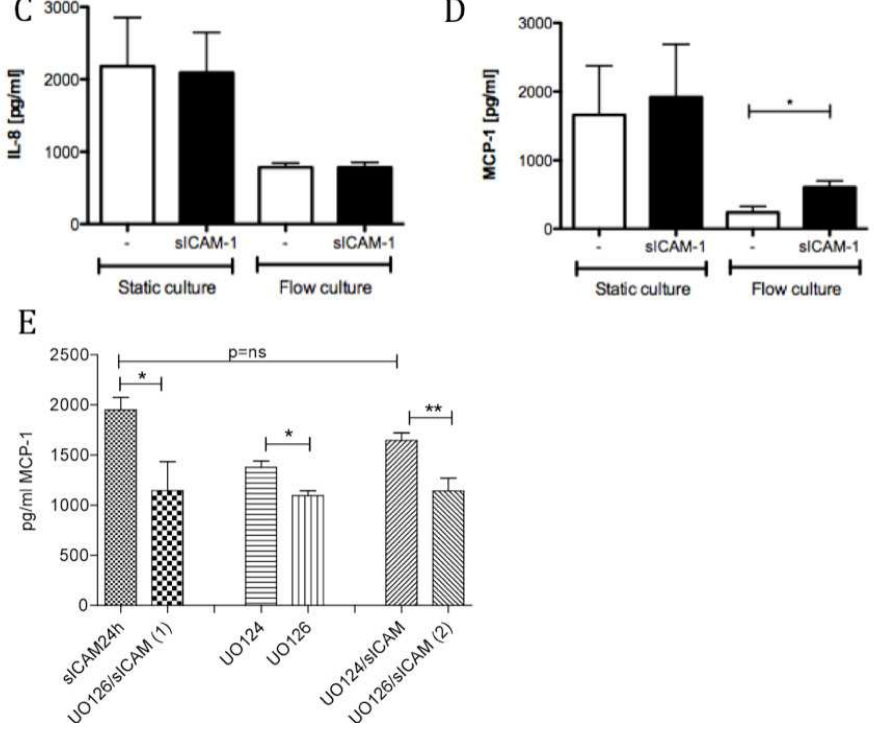

Fig. 6. Effect of sICAM-1 and shear stress on IL-8 and MCP-1 secretion in HUVEC. (A, B) mRNA for MCP-1 and IL-8 were measured in HUVEC in static culture following exposure to $100 \mathrm{ng} / \mathrm{ml}$ sICAM-1 for $1 \mathrm{hr}$. (C, D) HUVEC were grown in static culture or subjected to laminar shear forces of $10 \mathrm{dyn} / \mathrm{cm}^{2}$ in a parallel plate flow chamber and recirculating flow loop for $16 \mathrm{~h}$ to acclimatise before addition of $100 \mathrm{ng} / \mathrm{ml}$ sICAM-1 for a further $24 \mathrm{~h}$. Secretion of MCP-1 and IL-8 were measured by ELISA. (E) HUVEC were acclimatised to shear stress for 16hr before addition of MEK inhibitor U0126 $(1 \mu \mathrm{M})$ or the inactive analogue U0124 $(1 \mu \mathrm{M})$ followed by $100 \mathrm{ng} / \mathrm{ml}$ sICAM-1 for $24 \mathrm{hr}$. Secretion of MCP-1 and IL- 8 were measured by ELISA. $n=3$ separate isolates for each pair of conditions. ${ }^{*} p<0.05$ and ${ }^{* *} p<0.01$.

\section{Conclusions}

Our data suggest that the MEK-Erk pathway plays a role in sICAM-1 mediated MCP-1 production in HUVEC pre-exposed to laminar flow, and therefore that cleavage of ICAM-1 from the cell surface has a two fold effect; on the one hand providing a negative feedback mechanism to limit leukocyte adhesion and diapedesis, but on the other enhancing monocyte chemotaxis towards the endothelium. Thus sICAM-1 released into the circulation may be considered a pro-inflammatory mediator in the context of vascular inflammation and atherosclerosis progression. 
At this time, no receptor has been identified for sICAM-1 and none of the common ligands for ICAM-1, such as LFA-1 and Mac-1, are present on HUVEC either in the activated or resting state. Two potential candidates for receptors have been suggested so far, namely the homophilic binding to membrane bound ICAM-1, or an unknown receptor of $49 \mathrm{kD}$ (Gho, Kleinman et al. 1999; Otto, Gloor et al. 2002). Otto et al showed that sICAM-1 did not bind to cell surface ICAM-1 using ICAM-1 deficient murine astrocytes but identified the involvement of an unidentified receptor (Otto, Gloor et al. 2002). It is possible that the level of expression of this unknown receptor on the cell surface could vary under different flow conditions, for example the receptor could be regulated through activation of a shear stress response element (SSRE) and therefore result in different expression levels on EC depending on the kinetics and/or type of shear stress to which the cells have been exposed. Since prolonged exposure to flow increases ICAM-1 expression (Nagel, Resnick et al. 1994; Chiu, Wung et al. 1997) and an SSRE has been identified in the promoter for ICAM-1 (Nagel, Resnick et al. 1994) we speculate that cell surface ICAM-1 could act as a receptor for sICAM1 in the experiments presented here. Further experiments are necessary using blocking FAb fragments to ICAM-1 to determine this.

Experimental data obtained in vitro or in animal models together with data obtained from clinical samples indicates an important role for sICAM-1 within cardiovascular disease. More experimental studies are required to characterise the precise role of sICAM-1. By understanding the pathways and mechanisms involved in shedding sICAM-1 into the lumen and its role within the inflammation site, new potential methods to interfere with disease progression might become possible. In addition, larger clinical studies are also required to determine the potential use of sICAM-1 as non-invasive diagnostic biomarker for cardiovascular disease.

\section{Acknowledgements}

S.I.W was funded by a project grant from the British Heart Foundation.

\section{References}

Adamson, P., S. Etienne, et al. (1999). "Lymphocyte migration through brain endothelial cell monolayers involves signaling through endothelial ICAM-1 via a rho-dependent pathway." J Immunol 162(5): 2964-73.

Altieri, D. C., A. Duperray, et al. (1995). "Structural recognition of a novel fibrinogen gamma chain sequence (117-133) by intercellular adhesion molecule-1 mediates leukocyteendothelium interaction." J Biol Chem 270(2): 696-9.

Barbalic, M., J. Dupuis, et al. (2010). "Large-scale genomic studies reveal central role of ABO in sP-selectin and sICAM-1 levels." Hum Mol Genet 19(9): 1863-72.

Barreiro, O., M. Yanez-Mo, et al. (2002). "Dynamic interaction of VCAM-1 and ICAM-1 with moesin and ezrin in a novel endothelial docking structure for adherent leukocytes." J Cell Biol 157(7): 1233-45.

Becker, A., V. W. van Hinsbergh, et al. (2002). "Why is soluble intercellular adhesion molecule-1 related to cardiovascular mortality?" Eur J Clin Invest 32(1): 1-8.

Becker, J. C., R. Dummer, et al. (1991). "Shedding of ICAM-1 from human melanoma cell lines induced by IFN-gamma and tumor necrosis factor-alpha. Functional consequences on cell-mediated cytotoxicity." J Immunol 147(12): 4398-401. 
Bella, J. and M. G. Rossmann (1999). "Review: rhinoviruses and their ICAM receptors." J Struct Biol 128(1): 69-74.

Bemelmans, W. J., J. D. Lefrandt, et al. (2002). "Change in saturated fat intake is associated with progression of carotid and femoral intima-media thickness, and with levels of soluble intercellular adhesion molecule-1." Atherosclerosis 163(1): 113-20.

Bickel, C., H. J. Rupprecht, et al. (2002). "Influence of HMG-CoA reductase inhibitors on markers of coagulation, systemic inflammation and soluble cell adhesion." Int J Cardiol 82(1): 25-31.

Bielinski, S. J., J. S. Pankow, et al. (2008). "Circulating soluble ICAM-1 levels shows linkage to ICAM gene cluster region on chromosome 19: the NHLBI Family Heart Study follow-up examination." Atherosclerosis 199(1): 172-8.

Bielinski, S. J., J. S. Pankow, et al. (2008). "ICAM1 and VCAM1 polymorphisms, coronary artery calcium, and circulating levels of soluble ICAM-1: the multi-ethnic study of atherosclerosis (MESA)." Atherosclerosis 201(2): 339-44.

Bielinski, S. J., A. P. Reiner, et al. (2011). "Polymorphisms in the ICAM1 gene predict circulating soluble intercellular adhesion molecule-1(sICAM-1)." Atherosclerosis 216(2): 390-4.

Blankenberg, S., S. Barbaux, et al. (2003). "Adhesion molecules and atherosclerosis." Atherosclerosis 170(2): 191-203.

Blankenberg, S., H. J. Rupprecht, et al. (2001). "Circulating cell adhesion molecules and death in patients with coronary artery disease." Circulation 104(12): 1336-42.

Blann, A. D., D. Gurney, et al. (2001). "Influence of pravastatin on lipoproteins, and on endothelial, platelet, and inflammatory markers in subjects with peripheral artery disease." Am J Cardiol 88(1): A7-8, 89-92.

Bourdillon, M. C., R. N. Poston, et al. (2000). "ICAM-1 deficiency reduces atherosclerotic lesions in double-knockout mice (ApoE(-/-)/ICAM-1(-/-)) fed a fat or a chow diet." Arterioscler Thromb Vasc Biol 20(12): 2630-5.

Carpén, O., P. Pallai, et al. (1992). "Association of intercellular adhesion molecule-1 (ICAM1) with actin-containing cytoskeleton and alpha-actinin." J Cell Biol 118(5): 1223-34.

Champagne, B., P. Tremblay, et al. (1998). "Proteolytic cleavage of ICAM-1 by human neutrophil elastase." J Immunol 161(11): 6398-405.

Chen, K. D., Y. S. Li, et al. (1999). "Mechanotransduction in response to shear stress. Roles of receptor tyrosine kinases, integrins, and Shc." J Biol Chem 274(26): 18393-400.

Chihara, J., T. Yamamoto, et al. (1994). "Soluble ICAM-1 in sputum of patients with bronchial asthma." Lancet 343(8905): 1108.

Chiu, J. J., B. S. Wung, et al. (1997). "Reactive oxygen species are involved in shear stressinduced intercellular adhesion molecule-1 expression in endothelial cells." Arterioscler Thromb Vasc Biol 17(12): 3570-7.

Collins, C. and E. Tzima (2011). "Hemodynamic forces in endothelial dysfunction and vascular aging." Exp Gerontol 46(2-3): 185-8.

Cronstein, B. N., S. C. Kimmel, et al. (1992). "A mechanism for the antiinflammatory effects of corticosteroids: the glucocorticoid receptor regulates leukocyte adhesion to endothelial cells and expression of endothelial-leukocyte adhesion molecule 1 and intercellular adhesion molecule 1." Proc Natl Acad Sci U S A 89(21): 9991-5.

De Caterina, R., P. Libby, et al. (1995). "Nitric oxide decreases cytokine-induced endothelial activation. Nitric oxide selectively reduces endothelial expression of adhesion molecules and proinflammatory cytokines." J Clin Invest 96(1): 60-8. 
Durieu-Trautmann, O., N. Chaverot, et al. (1994). "Intercellular adhesion molecule 1 activation induces tyrosine phosphorylation of the cytoskeleton-associated protein cortactin in brain microvessel endothelial cells." J Biol Chem 269(17): 12536-40.

Dustin, M. L., R. Rothlein, et al. (1986). "Induction by IL 1 and interferon-gamma: tissue distribution, biochemistry, and function of a natural adherence molecule (ICAM1)." J Immunol 137(1): 245-54.

Etienne-Manneville, S., J. B. Manneville, et al. (2000). "ICAM-1-coupled cytoskeletal rearrangements and transendothelial lymphocyte migration involve intracellular calcium signaling in brain endothelial cell lines." J Immunol 165(6): 3375-83.

Etienne, S., P. Adamson, et al. (1998). "ICAM-1 signaling pathways associated with Rho activation in microvascular brain endothelial cells." J Immunol 161(10): 5755-61.

Federici, C., L. Camoin, et al. (1996). "Association of the cytoplasmic domain of intercellularadhesion molecule-1 with glyceraldehyde-3-phosphate dehydrogenase and betatubulin." Eur J Biochem 238(1): 173-80.

Florian, J. A., J. R. Kosky, et al. (2003). "Heparan sulfate proteoglycan is a mechanosensor on endothelial cells." Circ Res 93(10): e136-42.

Fonsatti, E., M. Altomonte, et al. (1997). "Tumour-derived interleukin 1alpha (IL-1alpha) upregulates the release of soluble intercellular adhesion molecule-1 (sICAM-1) by endothelial cells." Br J Cancer 76(10): 1255-61.

Frank, P. G. and M. P. Lisanti (2006). "Role of caveolin-1 in the regulation of the vascular shear stress response." J Clin Invest 116(5): 1222-5.

Frostegård J. (2011). "Cardiovascular co-morbidity in patients with rheumatic diseases." Arthritis Res Ther. 13(3):225.

Fujiwara, K., M. Masuda, et al. (2001). "Is PECAM-1 a mechanoresponsive molecule?" Cell Struct Funct 26(1): 11-7.

Gaetani, E., A. Flex, et al. (2002). "The K469E polymorphism of the ICAM-1 gene is a risk factor for peripheral arterial occlusive disease." Blood Coagul Fibrinolysis 13(6): 483-8.

Gaglia, J. L., E. A. Greenfield, et al. (2000). "Intercellular adhesion molecule 1 is critical for activation of CD28-deficient T cells." J Immunol 165(11): 6091-8.

Gearing, A. J. and W. Newman (1993). "Circulating adhesion molecules in disease." Immunol Today 14(10): 506-12.

Gerszten, R. E., E. A. Garcia-Zepeda, et al. (1999). "MCP-1 and IL-8 trigger firm adhesion of monocytes to vascular endothelium under flow conditions." Nature 398(6729): 71823.

Gho, Y. S., P. N. Kim, et al. (2001). "Stimulation of tumor growth by human soluble intercellular adhesion molecule-1." Cancer Res 61(10): 4253-7.

Gho, Y. S., H. K. Kleinman, et al. (1999). "Angiogenic activity of human soluble intercellular adhesion molecule-1." Cancer Res 59(20): 5128-32.

Gimbrone, M. A., J. N. Topper, et al. (2000). "Endothelial dysfunction, hemodynamic forces, and atherogenesis." Ann N Y Acad Sci 902: 230-9; discussion 239-40.

Grakoui, A., S. K. Bromley, et al. (1999). "The immunological synapse: a molecular machine controlling T cell activation." Science 285(5425): 221-7.

Greenwood, J., Y. Wang, et al. (1995). "Lymphocyte adhesion and transendothelial migration in the central nervous system: the role of LFA-1, ICAM-1, VLA-4 and VCAM-1. off." Immunology 86(3): 408-15. 
Greve, J. M., G. Davis, et al. (1989). "The major human rhinovirus receptor is ICAM-1." Cell 56(5): 839-47.

Gudi, S. R., C. B. Clark, et al. (1996). "Fluid flow rapidly activates G proteins in human endothelial cells. Involvement of $G$ proteins in mechanochemical signal transduction." Circ Res 79(4): 834-9.

Haim, M., D. Tanne, et al. (2002). "Soluble intercellular adhesion molecule-1 and long-term risk of acute coronary events in patients with chronic coronary heart disease. Data from the Bezafibrate Infarction Prevention (BIP) Study." J Am Coll Cardiol 39(7): 1133-8.

Hansson, G. K. and P. Libby (2006). "The immune response in atherosclerosis: a doubleedged sword." Nat Rev Immunol 6(7): 508-19.

Hansson G.K. (2009). "Inflammatory mechanisms in atherosclerosis." J Thromb Haemost. 7 Suppl 1:328-31

Helmlinger, G., B. C. Berk, et al. (1996). "Pulsatile and steady flow-induced calcium oscillations in single cultured endothelial cells." J Vasc Res 33(5): 360-9.

Hoffmeister A, Rothenbacher D, et al. (2001). "Current infection with Helicobacter pylori, but not seropositivity to Chlamydia pneumoniae or cytomegalovirus, is associated with an atherogenic, modified lipid profile." Arterioscler Thromb Vasc Biol. 21(3):42732.

Holder A.L., S. Wolf, et al (2008) “Expression of endothelial intercellular adhesion molecule1 is determined by genotype: effects on efficiency of leukocyte adhesion to human endothelial cells." Hum Immunol. 69:71-8

Holland, J. and T. Owens (1997). "Signaling through intercellular adhesion molecule 1 (ICAM-1) in a B cell lymphoma line. The activation of Lyn tyrosine kinase and the mitogen-activated protein kinase pathway." J Biol Chem 272(14): 9108-12.

Hwang, S. J., C. M. Ballantyne, et al. (1997). "Circulating adhesion molecules VCAM-1, ICAM-1, and E-selectin in carotid atherosclerosis and incident coronary heart disease cases: the Atherosclerosis Risk In Communities (ARIC) study." Circulation 96(12): 4219-25.

Jiang, H., R. M. Klein, et al. (2002). "C/T polymorphism of the intercellular adhesion molecule-1 gene (exon 6, codon 469). A risk factor for coronary heart disease and myocardial infarction." Int J Cardiol 84(2-3): 171-7.

Jilma, B., C. Joukhadar, et al. (2003). "Levels of adhesion molecules do not decrease after 3 months of statin therapy in moderate hypercholesterolaemia." Clin Sci (Lond) 104(2): 189-93.

Karalliedde J., and G. Viberti (2004)."Microalbuminuria and cardiovascular risk." Am J Hypertens. 17(10):986-93.

Kent, J. W., M. C. Mahaney, et al. (2007). "Quantitative trait locus on Chromosome 19 for circulating levels of intercellular adhesion molecule-1 in Mexican Americans." Atherosclerosis 195(2): 367-73.

Kirchhausen, T., D. E. Staunton, et al. (1993). "Location of the domains of ICAM-1 by immunolabeling and single-molecule electron microscopy." J Leukoc Biol 53(3): 342-6.

Kitagawa, K., M. Matsumoto, et al. (2002). "Involvement of ICAM-1 in the progression of atherosclerosis in APOE-knockout mice." Atherosclerosis 160(2): 305-10. 
Languino, L. R., A. Duperray, et al. (1995). "Regulation of leukocyte-endothelium interaction and leukocyte transendothelial migration by intercellular adhesion molecule 1fibrinogen recognition." Proc Natl Acad Sci U S A 92(5): 1505-9.

Languino, L. R., J. Plescia, et al. (1993). "Fibrinogen mediates leukocyte adhesion to vascular endothelium through an ICAM-1-dependent pathway." Cell 73(7): 1423-34.

Lavie C.J., R.V. Milani, H.O. Ventura. (2009). Obesity and cardiovascular disease: risk factor, paradox, and impact of weight loss. J Am Coll Cardiol. 53(21):1925-32.

Laurila A, Bloigu A, et al. (1997). "Chronic Chlamydia pneumoniae infection is associated with a serum lipid profile known to be a risk factor for atherosclerosis." Arterioscler Thromb Vasc Biol. 17(11):2910-3.

Lawson, C., M. Ainsworth, et al. (1999). "Ligation of ICAM-1 on endothelial cells leads to expression of VCAM-1 via a nuclear factor-kappaB-independent mechanism." J Immunol 162(5): 2990-6.

Lawson, C., M. E. Ainsworth, et al. (2001). "Effects of cross-linking ICAM-1 on the surface of human vascular smooth muscle cells: induction of VCAM-1 but no proliferation." Cardiovasc Res 50(3): 547-55.

Lawson, C., A. L. Holder, et al. (2005). "Anti-intercellular adhesion molecule-1 antibodies in sera of heart transplant recipients: a role in endothelial cell activation." Transplantation 80(2): 264-71.

Lawson, C. and S.I. Wolf. (2009). "ICAM-1 signaling in endothelial cells." Pharmacol Rep. 61(1):22-32.

Lawson C, M. Rose and S. Wolf. (2010) Leucocyte adhesion under haemodynamic flow conditions. Methods Mol Biol. 616:31-47.

Leeuwenberg, J. F., E. F. Smeets, et al. (1992). "E-selectin and intercellular adhesion molecule-1 are released by activated human endothelial cells in vitro." Immunology 77(4): 543-9.

Lehmann, J. C., D. Jablonski-Westrich, et al. (2003). "Overlapping and selective roles of endothelial intercellular adhesion molecule-1 (ICAM-1) and ICAM-2 in lymphocyte trafficking." J Immunol 171(5): 2588-93.

Lehoux, S., Y. Castier, et al. (2006). "Molecular mechanisms of the vascular responses to haemodynamic forces." J Intern Med 259(4): 381-92.

Leung, K. H. (1999). "Release of soluble ICAM-1 from human lung fibroblasts, aortic smooth muscle cells, dermal microvascular endothelial cells, bronchial epithelial cells, and keratinocytes." Biochem Biophys Res Commun 260(3): 734-9.

Ley, K., C. Laudanna, et al. (2007). "Getting to the site of inflammation: the leukocyte adhesion cascade updated." Nat Rev Immunol 7(9): 678-89.

Li, Y. S., J. H. Haga, et al. (2005). "Molecular basis of the effects of shear stress on vascular endothelial cells." J Biomech 38(10): 1949-71.

Lindemann, S., M. Sharafi, et al. (2000). "NO reduces PMN adhesion to human vascular endothelial cells due to downregulation of ICAM-1 mRNA and surface expression." Thromb Res 97(3): 113-23.

Lusis, A. J. (2000). "Atherosclerosis." Nature 407(6801): 233-41.

Lyck, R., Y. Reiss, et al. (2003). "T-cell interaction with ICAM-1/ICAM-2 double-deficient brain endothelium in vitro: the cytoplasmic tail of endothelial ICAM-1 is necessary for transendothelial migration of T cells." Blood 102(10): 3675-83. 
Lyons, P. D. and E. N. Benveniste (1998). "Cleavage of membrane-associated ICAM-1 from astrocytes: involvement of a metalloprotease." Glia 22(2): 103-12.

Macey M.G., S.I. Wolf, C.P. Wheeler-Jones and C. Lawson. (2009) "Expression of blood coagulation factors on monocytes after exposure to TNF-treated endothelium in a novel whole blood model of arterial flow." J Immunol Methods. 350(1-2):133-41.

Macey M.G., S.I. Wolf, C. Lawson (2010). "Microparticle formation after exposure of blood to activated endothelium under flow." Cytometry A. 77(8):761-8.

Malik, I., J. Danesh, et al. (2001). "Soluble adhesion molecules and prediction of coronary heart disease: a prospective study and meta-analysis." Lancet 358(9286): 971-6.

Malyszko, J. (2010). "Mechanism of endothelial dysfunction in chronic kidney disease." Clin Chim Acta 411(19-20): 1412-20.

Marlin, S. D. and T. A. Springer (1987). "Purified intercellular adhesion molecule-1 (ICAM-1) is a ligand for lymphocyte function-associated antigen 1 (LFA-1)." Cell 51(5): 813-9.

Marlin, S. D., D. E. Staunton, et al. (1990). "A soluble form of intercellular adhesion molecule-1 inhibits rhinovirus infection." Nature 344(6261): 70-2.

Martin, S., A. Martin, et al. (1993). "Functional studies of truncated soluble intercellular adhesion molecule 1 expressed in Escherichia coli." Antimicrob Agents Chemother 37(6): 1278-84.

Mason, J. C., P. Kapahi, et al. (1993). "Detection of increased levels of circulating intercellular adhesion molecule 1 in some patients with rheumatoid arthritis but not in patients with systemic lupus erythematosus. Lack of correlation with levels of circulating vascular cell adhesion molecule 1." Arthritis Rheum 36(4): 519-27.

Metallo, C. M., M. A. Vodyanik, et al. (2008). "The response of human embryonic stem cellderived endothelial cells to shear stress." Biotechnol Bioeng 100(4): 830-7.

Nageh, M. F., E. T. Sandberg, et al. (1997). "Deficiency of inflammatory cell adhesion molecules protects against atherosclerosis in mice." Arterioscler Thromb Vasc Biol 17(8): 1517-20.

Nagel, T., N. Resnick, et al. (1994). "Shear stress selectively upregulates intercellular adhesion molecule-1 expression in cultured human vascular endothelial cells." $J$ Clin Invest 94(2): 885-91.

Ockenhouse, C. F., R. Betageri, et al. (1992). "Plasmodium falciparum-infected erythrocytes bind ICAM-1 at a site distinct from LFA-1, Mac-1, and human rhinovirus." Cell 68(1): 63-9.

Ockenhouse, C. F., M. Ho, et al. (1991). "Molecular basis of sequestration in severe and uncomplicated Plasmodium falciparum malaria: differential adhesion of infected erythrocytes to CD36 and ICAM-1." J Infect Dis 164(1): 163-9.

Ockenhouse, C. F., T. Tegoshi, et al. (1992). "Human vascular endothelial cell adhesion receptors for Plasmodium falciparum-infected erythrocytes: roles for endothelial leukocyte adhesion molecule 1 and vascular cell adhesion molecule 1." J Exp Med 176(4): 1183-9.

Oh, H. M., S. Lee, et al. (2007). "RKIKK motif in the intracellular domain is critical for spatial and dynamic organization of ICAM-1: functional implication for the leukocyte adhesion and transmigration." Mol Biol Cell 18(6): 2322-35.

Ohno, M., J. P. Cooke, et al. (1995). "Fluid shear stress induces endothelial transforming growth factor beta-1 transcription and production. Modulation by potassium channel blockade." J Clin Invest 95(3): 1363-9. 
Osawa, M., M. Masuda, et al. (2002). "Evidence for a role of platelet endothelial cell adhesion molecule-1 in endothelial cell mechanosignal transduction: is it a mechanoresponsive molecule?" J Cell Biol 158(4): 773-85.

Otto, V. I., S. M. Gloor, et al. (2002). "The production of macrophage inflammatory protein-2 induced by soluble intercellular adhesion molecule- 1 in mouse astrocytes is mediated by src tyrosine kinases and p42/44 mitogen-activated protein kinase." $J$ Neurochem 80(5): 824-34.

Otto, V. I., U. E. Heinzel-Pleines, et al. (2000). "sICAM-1 and TNF-alpha induce MIP-2 with distinct kinetics in astrocytes and brain microvascular endothelial cells." J Neurosci Res 60(6): 733-42.

Patel, S. S., R. Thiagarajan, et al. (1998). "Inhibition of alpha4 integrin and ICAM-1 markedly attenuate macrophage homing to atherosclerotic plaques in ApoE-deficient mice." Circulation 97(1): 75-81.

Pigott, R., L. P. Dillon, et al. (1992). "Soluble forms of E-selectin, ICAM-1 and VCAM-1 are present in the supernatants of cytokine activated cultured endothelial cells." Biochem Biophys Res Commun 187(2): 584-9.

Pluskota, E., Y. Chen, et al. (2000). "Src homology domain 2-containing tyrosine phosphatase 2 associates with intercellular adhesion molecule 1 to regulate cell survival." J Biol Chem 275(39): 30029-36.

Pluskota, E. and S. E. D'Souza (2000). "Fibrinogen interactions with ICAM-1 (CD54) regulate endothelial cell survival." Eur J Biochem 267(15): 4693-704.

Pober, J. S., M. A. Gimbrone, et al. (1986). "Overlapping patterns of activation of human endothelial cells by interleukin 1, tumor necrosis factor, and immune interferon." $J$ Immunol 137(6): 1893-6.

Poston, R. N., D. O. Haskard, et al. (1992). "Expression of intercellular adhesion molecule-1 in atherosclerotic plaques." Am J Pathol 140(3): 665-73.

Rauch, U., J. I. Osende, et al. (2000). "Statins and cardiovascular diseases: the multiple effects of lipid-lowering therapy by statins." Atherosclerosis 153(1): 181-9.

Reiss, Y. and B. Engelhardt (1999). "T cell interaction with ICAM-1-deficient endothelium in vitro: transendothelial migration of different $\mathrm{T}$ cell populations is mediated by endothelial ICAM-1 and ICAM-2." Int Immunol 11(9): 1527-39.

Renkonen, R., P. Mattila, et al. (1992). "IL-4 decreases IFN-gamma-induced endothelial ICAM-1 expression by a transcriptional mechanism." Scand J Immunol 35(5): 525-30.

Resnick, N., H. Yahav, et al. (2003). "Fluid shear stress and the vascular endothelium: for better and for worse." Prog Biophys Mol Biol 81(3): 177-99.

Ridker, P. M., J. E. Buring, et al. (2001). "Soluble P-selectin and the risk of future cardiovascular events." Circulation 103(4): 491-5.

Ridker, P. M., C. H. Hennekens, et al. (1998). "Plasma concentration of soluble intercellular adhesion molecule 1 and risks of future myocardial infarction in apparently healthy men." Lancet 351(9096): 88-92.

Romano, M., A. Mezzetti, et al. (2000). "Fluvastatin reduces soluble P-selectin and ICAM-1 levels in hypercholesterolemic patients: role of nitric oxide." J Investig Med 48(3): 183-9.

Ross, R. (1999). "Atherosclerosis--an inflammatory disease." N Engl J Med 340(2): 115-26.

Ross, R. and J. Glomset (1974). "Studies of primate arterial smooth muscle cells in relation to atherosclerosis." Adv Exp Med Biol 43(0): 265-79. 
Rothlein, R., T. K. Kishimoto, et al. (1994). "Cross-linking of ICAM-1 induces co-signaling of an oxidative burst from mononuclear leukocytes." J Immunol 152(5): 2488-95.

Rothlein, R., E. A. Mainolfi, et al. (1991). "A form of circulating ICAM-1 in human serum." J Immunol 147(11): 3788-93.

Sampath, R., G. L. Kukielka, et al. (1995). "Shear stress-mediated changes in the expression of leukocyte adhesion receptors on human umbilical vein endothelial cells in vitro." Ann Biomed Eng 23(3): 247-56.

Sano, H., N. Nakagawa, et al. (1998). "Cross-linking of intercellular adhesion molecule-1 induces interleukin-8 and RANTES production through the activation of MAP kinases in human vascular endothelial cells." Biochem Biophys Res Commun 250(3): 694-8.

Schwenke, D. C. and T. E. Carew (1989a). "Initiation of atherosclerotic lesions in cholesterolfed rabbits. I. Focal increases in arterial LDL concentration precede development of fatty streak lesions." Arteriosclerosis 9(6): 895-907.

Schwenke, D. C. and T. E. Carew (1989b). "Initiation of atherosclerotic lesions in cholesterolfed rabbits. II. Selective retention of LDL vs. selective increases in LDL permeability in susceptible sites of arteries." Arteriosclerosis 9(6): 908-18.

Seth, R., F. D. Raymond, et al. (1991). "Circulating ICAM-1 isoforms: diagnostic prospects for inflammatory and immune disorders." Lancet 338(8759): 83-4.

Shijubo, N., K. Imai, et al. (1994). "Soluble intercellular adhesion molecule-1 (ICAM-1) in sera and bronchoalveolar lavage fluid of patients with idiopathic pulmonary fibrosis and pulmonary sarcoidosis." Clin Exp Immunol 95(1): 156-61.

Shyy, J. Y. and S. Chien (2002). "Role of integrins in endothelial mechanosensing of shear stress." Circ Res 91(9): 769-75.

Skålén, K., M. Gustafsson, et al. (2002). "Subendothelial retention of atherogenic lipoproteins in early atherosclerosis." Nature 417(6890): 750-4.

Sligh, J. E., C. M. Ballantyne, et al. (1993). "Inflammatory and immune responses are impaired in mice deficient in intercellular adhesion molecule 1." Proc Natl Acad Sci U S A 90(18): 8529-33.

Smith, C. W., S. D. Marlin, et al. (1989). "Cooperative interactions of LFA-1 and Mac-1 with intercellular adhesion molecule- 1 in facilitating adherence and transendothelial migration of human neutrophils in vitro." J Clin Invest 83(6): 2008-17.

Springer, T. A. (1994). "Traffic signals for lymphocyte recirculation and leukocyte emigration: the multistep paradigm." Cell 76(2): 301-14.

Staunton, D. E., S. D. Marlin, et al. (1988). "Primary structure of ICAM-1 demonstrates interaction between members of the immunoglobulin and integrin supergene families." Cell 52(6): 925-33.

Staunton, D. E., V. J. Merluzzi, et al. (1989). "A cell adhesion molecule, ICAM-1, is the major surface receptor for rhinoviruses." Cell 56(5): 849-53.

Surapisitchat, J., R. J. Hoefen, et al. (2001). "Fluid shear stress inhibits TNF-alpha activation of JNK but not ERK1/2 or p38 in human umbilical vein endothelial cells: Inhibitory crosstalk among MAPK family members." Proc Natl Acad Sci U S A 98(11): 6476-81.

Tang, W., J. S. Pankow, et al. (2007). "Association of sICAM-1 and MCP-1 with coronary artery calcification in families enriched for coronary heart disease or hypertension: the NHLBI Family Heart Study." BMC Cardiovasc Disord 7: 30. 
Tarín, C., M. Gomez, et al. (2009). "Endothelial nitric oxide deficiency reduces MMP-13mediated cleavage of ICAM-1 in vascular endothelium: a role in atherosclerosis." Arterioscler Thromb Vasc Biol 29(1): 27-32.

Teppo, A. M., E. von Willebrand, et al. (2001). "Soluble intercellular adhesion molecule-1 (sICAM-1) after kidney transplantation: the origin and role of urinary sICAM-1?" Transplantation 71(8): 1113-9.

Thi, M. M., J. M. Tarbell, et al. (2004). "The role of the glycocalyx in reorganization of the actin cytoskeleton under fluid shear stress: a "bumper-car" model." Proc Natl Acad Sci U S A 101(47): 16483-8.

Thompson, P. W., A. M. Randi, et al. (2002). "Intercellular adhesion molecule (ICAM)-1, but not ICAM-2, activates RhoA and stimulates c-fos and rhoA transcription in endothelial cells." J Immunol 169(2): 1007-13.

Tsakadze, N. L., U. Sen, et al. (2004). "Signals mediating cleavage of intercellular adhesion molecule-1." Am J Physiol Cell Physiol 287(1): C55-63.

Tsakadze, N. L., S. D. Sithu, et al. (2006). "Tumor necrosis factor-alpha-converting enzyme (TACE/ADAM-17) mediates the ectodomain cleavage of intercellular adhesion molecule-1 (ICAM-1)." J Biol Chem 281(6): 3157-64.

Tsakadze, N. L., Z. Zhao, et al. (2002). "Interactions of intercellular adhesion molecule-1 with fibrinogen." Trends Cardiovasc Med 12(3): 101-8.

Tsukada, N., M. Matsuda, et al. (1993). "Increased levels of intercellular adhesion molecule-1 (ICAM-1) and tumor necrosis factor receptor in the cerebrospinal fluid of patients with multiple sclerosis." Neurology 43(12): 2679-82.

Tzima, E., M. A. del Pozo, et al. (2001). "Activation of integrins in endothelial cells by fluid shear stress mediates Rho-dependent cytoskeletal alignment." EMBO J 20(17): 463947.

van Buul, J. D. and P. L. Hordijk (2004). "Signaling in leukocyte transendothelial migration." Arterioscler Thromb Vasc Biol 24(5): 824-33.

van de Stolpe, A. and P. T. van der Saag (1996). "Intercellular adhesion molecule-1." J Mol Med 74(1): 13-33.

Van der Heiden, K., B. C. Groenendijk, et al. (2006). "Monocilia on chicken embryonic endocardium in low shear stress areas." Dev Dyn 235(1): 19-28.

Van der Heiden, K., B. P. Hierck, et al. (2008). "Endothelial primary cilia in areas of disturbed flow are at the base of atherosclerosis." Atherosclerosis 196(2): 542-50.

Wakatsuki, T., K. Kimura, et al. (1995). "A distinct mRNA encoding a soluble form of ICAM1 molecule expressed in human tissues." Cell Adhes Commun 3(4): 283-92.

Wallén, N. H., C. Held, et al. (1999). "Elevated serum intercellular adhesion molecule-1 and vascular adhesion molecule- 1 among patients with stable angina pectoris who suffer cardiovascular death or non-fatal myocardial infarction." Eur Heart J 20(14): 1039-43.

Wang, Q., G. R. Pfeiffer, et al. (2003). "Activation of SRC tyrosine kinases in response to ICAM-1 ligation in pulmonary microvascular endothelial cells." J Biol Chem 278(48): 47731-43.

Williams, K. J. and I. Tabas (1995). "The response-to-retention hypothesis of early atherogenesis." Arterioscler Thromb Vasc Biol 15(5): 551-61.

Witkowska, A. M. and M. H. Borawska (2004). "Soluble intercellular adhesion molecule-1 (sICAM-1): an overview." Eur Cytokine Netw 15(2): 91-8. 
Wójciak-Stothard, B., L. Williams, et al. (1999). "Monocyte adhesion and spreading on human endothelial cells is dependent on Rho-regulated receptor clustering." J Cell Biol 145(6): 1293-307.

Yamamoto, K., R. Korenaga, et al. (2000). "Fluid shear stress activates $\mathrm{Ca}(2+)$ influx into human endothelial cells via P2X4 purinoceptors." Circ Res 87(5): 385-91. 


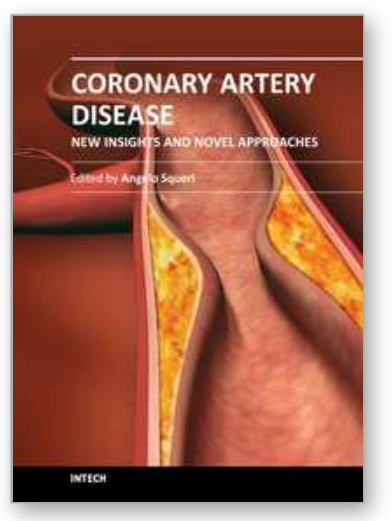

\author{
Coronary Artery Disease - New Insights and Novel Approaches \\ Edited by Dr. Angelo Squeri
}

ISBN 978-953-51-0344-8

Hard cover, 260 pages

Publisher InTech

Published online 16, March, 2012

Published in print edition March, 2012

Coronary Artery disease is one of the leading causes of death in industrialized countries and is responsible for one out of every six deaths in the United States. Remarkably, coronary artery disease is also largely preventable. The biggest challenge in the next years is to reduce the incidence of coronary artery disease worldwide. A complete knowledge of the mechanisms responsible for the development of ischaemic heart disease is an essential prerequisite to a better management of this pathology improving prevention and therapy. This book has been written with the intention of providing new concepts about coronary artery disease pathogenesis that may link various aspects of the disease, going beyond the traditional risk factors.

\title{
How to reference
}

In order to correctly reference this scholarly work, feel free to copy and paste the following:

Sabine I. Wolf and Charlotte Lawson (2012). ICAM-1: Contribution to Vascular Inflammation and Early Atherosclerosis, Coronary Artery Disease - New Insights and Novel Approaches, Dr. Angelo Squeri (Ed.), ISBN: 978-953-51-0344-8, InTech, Available from: http://www.intechopen.com/books/coronary-artery-diseasenew-insights-and-novel-approaches/icam-1-contribution-to-vascular-inflammation-and-early-atherosclerosis

\section{INTECH}

open science | open minds

\section{InTech Europe}

University Campus STeP Ri Slavka Krautzeka 83/A 51000 Rijeka, Croatia Phone: +385 (51) 770447

Fax: +385 (51) 686166 www.intechopen.com

\section{InTech China}

Unit 405, Office Block, Hotel Equatorial Shanghai No.65, Yan An Road (West), Shanghai, 200040, China 中国上海市延安西路65号上海国际贵都大饭店办公楼 405 单元 Phone: +86-21-62489820

Fax: $+86-21-62489821$ 
(C) 2012 The Author(s). Licensee IntechOpen. This is an open access article distributed under the terms of the Creative Commons Attribution 3.0 License, which permits unrestricted use, distribution, and reproduction in any medium, provided the original work is properly cited. 